\title{
TENSIONES ENTRE LA PROPIEDAD CIVIL Y LA PROPIEDAD INDÍGENA: CONSIDERACIONES DE DERECHO PRIVADO A PROPÓSITO DE LA DEMANDA TERRITORIAL MAPUCHE
}

Tensions between civil property and indigenous property: considerations of private law regarding mapuche's territorial demand

\author{
Hugo CÁRdenAS VILLARREAL* \\ Universidad de Chile
}

\section{RESUMEN}

La ley 19.253 de 1993 incorporó al ordenamiento jurídico chileno un nuevo tipo o modelo de propiedad, y un nuevo orden de protección y promoción de las tierras indígenas. Este trabajo analiza los problemas de adscripción y de eficacia de los actos y contratos sobre esas tierras, que genera la interacción del modelo alternativo de propiedad y el modelo del derecho común que dispone el Código Civil. El análisis de la interpretación jurisprudencial de la normativa general y especial muestra una tendencia a la protección de las tierras indígenas que satisface el principio protectorio consagrado en la ley.

\section{PALABRAs CLAVE}

Conflicto territorial, propiedad indígena, ineficacia de actos y negocios sobre tierra indígena.

\section{ABSTRACT}

The act 19.253 of 1993 incorporated to the Chilean legal system a new property type and a new protection and development order for indigenous land. This paper analyzes the land's adscription problems and the contract's effectiveness problems that involves indigenous lands, that are generated by the interaction between the alternative property model with the civil property model, provided by the Civil Code. An analysis of the jurisprudential interpretation of the general and special rules, shows a tendency towards the protection of indigenous lands that satisfies the protective principle enshrined in the law.

\section{KEYWORDS}

Territorial conflict, indigenous property, ineffectiveness of acts and business on indigenous land.

\section{Introducción}

En Chile, la ordenación territorial de las comunidades indígenas y, en especial, del denominado "espacio mapuche", dan cuenta de un constante intento estatal por asimilar las prácticas tradicionales de tenencia de tierras al esquema de propiedad consignado en el Código $\mathrm{Civil}^{1}$. Lo anterior, aparte de las consecuencias negativas que conlleva la incorporación de conceptos extraños a la cosmovisión mapuche (p. e., la propiedad colectiva civil), genera grandes dificultades de entendimiento puesto que la normativa estatal presupone una definición de lo que son tierras indígenas que no necesariamente coincide con lo que estiman las comunidades ${ }^{2}$. Pero, como los pueblos indígenas se han valido de esa normativa estatal para evitar la pérdida

\footnotetext{
* Profesor Asociado adscrito al Departamento de Derecho Privado de la Facultad de Derecho de la Universidad de Chile, Santiago, Chile. Correo electrónico: hcardenas@derecho.uchile.cl.

1 “El tenor de la legislación indígena de Chile es, desde 1813, siempre el mismo: legislar sobre la forma que más convenga, para conseguir la división de la comunidad indígena de propiedad territorial inalienable, con el fin expreso de transformarla en propiedad territorial individual alienable". LIPSCHUTZ (1956), p. 144.
}

${ }^{2}$ MÍGUEZ (2013), p. 41. 
de aquellas tierras cuya tenencia y dominio les fue reconocido entre finales del siglo XIX y principios del $X X$, se ha interpretado que su demanda coincide con el presupuesto de la legislación.

Por lo anterior, se ha dicho que la defensa judicial de las tierras entregadas en el periodo de radicación ha hecho que la reclamación territorial mapuche se haya interpretado y comprendido desde una doble óptica jurídico-occidental que no refleja la realidad y que, por lo tanto, forma parte del problema ${ }^{3}$. Así, por un lado, se ha entendido que se trata de demandas relativas a la noción eminentemente material del territorio (la tierra como bien productivo), asociada al concepto de propiedad civil; $y$, por otro lado, que el reclamo se limita al reconocimiento de títulos pro-indiviso (propiedad colectiva civil) instituidos por el Estado chileno durante el llamado "periodo de radicación" 4 .

Para algunos historiadores mapuche el reclamo de tierra no sólo cubre los terrenos radicados, sino también aquellas montañas, pampas, estepas y litorales que, aunque no tenían poblamiento permanente, eran utilizados por el pueblo mapuche en sus diferentes actividades vitales $^{5}$. Desde esta segunda perspectiva, el conflicto se amplifica en términos cuantitativos y cualitativos en tanto que, por un lado, aumenta sustancialmente la superficie reclamada; $y$, por otro, queda en evidencia que la forma de acceso y uso que se demanda de algunos territorios, no se aviene bien con los instrumentos conceptuales que hasta la fecha se han utilizado (especialmente con la noción de propiedad civil, individual o colectiva).

Con independencia de la perspectiva que se adopte, lo cierto es que con posterioridad a la prolongada operación de este sistema de reglas que buscaba la asimilación indígena se dictó la legislación protectora (no asimilacionista) que rige hasta la fecha: la Ley 19.253 de 1993 de Desarrollo Indígena (LDI). Y es un hecho que esa normativa incorporó al ordenamiento jurídico chileno un nuevo tipo de propiedad: "propiedad indígena" 6 .

El presente trabajo tiene como objetivo estudiar la forma en que se incorporó este modelo alternativo de propiedad al ordenamiento jurídico chileno, identificar los grandes polos de tensión que provoca su convivencia con el modelo de propiedad del derecho común del Código Civil, y analizar la jurisprudencia que se ha vertido en torno a la eficacia de los actos y contratos que afectan a la propiedad indígena. Sostendremos como hipótesis, que una armónica interpretación de la normativa nacional e internacional aplicable, impedirá que se desafecte una propiedad indígena fuera del procedimiento reglado por la LDI.

Estructuralmente, el trabajo se encuentra dividido en dos partes: en la primera, se realizarán algunas apreciaciones sobre la reivindicación territorial mapuche en el marco de la evolución histórica y jurídica que ha tenido la propiedad indígena, lo que es fundamental para identificar los principales polos de tensión que la actual normativa indígena genera en su interacción con el modelo del derecho civil. En la segunda, se abordarán los problemas concretos de eficacia de actos y contratos que hasta la fecha han exteriorizado tales tensiones en los tribunales del país.

\section{La reivindicación territorial del pueblo mapuche y las tensiones que genera la convivencia de dos modelos de propiedad}

Las tensiones que genera la convivencia de los dos modelos de propiedad referidos no se entienden cabalmente, si no se tiene al menos una idea de la reivindicación territorial del pueblo mapuche, y si no se analizan una serie de antecedentes normativos que se fueron sucediendo en el tiempo, desde los albores de la república chilena hasta el periodo de la vuelta a la democracia en los años noventa? ${ }^{7}$.

\footnotetext{
${ }^{3}$ MÍGUEZ (2013), p. 42.

${ }^{4}$ BENGOA (2000); y TOLEDO (2006), pp. 103 y ss.

${ }^{5}$ CANIUQUEO (2006), pp. 129 y ss.

${ }^{6}$ TAPIA (2005), pp. 167 y ss.

${ }^{7}$ Sobre este cambio social y político de la sociedad chilena puede verse: INDÍGENAS, COMISIÓN VERDAD HISTÓRICA Y NUEVO TRATO CON LOS PUEBLOS (2003), pp. 35 y ss.
} 


\subsection{La propiedad del derecho común como pieza fundacional de la república chilena y fundamento de la demanda territorial del pueblo mapuche}

La entrada en vigor del Código Civil en el año 1857 es un hito importante en el proceso normativo que propició una considerable pérdida de tierras que históricamente habían pertenecido al pueblo mapuche. En efecto, una de las razones que permite explicar dicha pérdida es que el modelo de propiedad que se implementó requería de un título (generalmente un contrato) y de un modo (una inscripción registral) para adquirir el dominio. En este modelo, el dominio sobre un terreno sólo puede transferirse (y probarse) mediante su correspondiente inscripción registral. Como se comprenderá fácilmente, el modelo descrito no da los mismos resultados, cuando se trata de determinar quién es el propietario de un bien raíz, que el modelo de propiedad de una cultura que le otorgaba al título fuerza suficiente para transferir y probar el dominio ${ }^{8}$.

Como se verá enseguida, la evolución del conflicto territorial llevó a que el Estado chileno les reconociera a las comunidades mapuche, mediante el modelo de propiedad del Código Civil, el dominio sobre algunos predios determinados. Sin embargo, debido en parte a la regulación que se le dio a esas propiedades, con el paso del tiempo las comunidades perdieron el dominio de muchas de esas tierras. Por lo anterior, es que una de las versiones de la demanda territorial mapuche dice relación con la devolución de las tierras que les fueron reconocidas por el Estado en el periodo de radicación y que, con posterioridad, perdieron (aproximadamente 250.000 hectáreas).

Como ya se adelantó, un análisis de la normativa vertida hasta la promulgación de la LDI permitirá comprender de mejor manera la forma en que se aplicó el modelo liberal del derecho civil al espacio mapuche, la demanda territorial actual, y las tensiones que la actual normativa genera con dicho modelo.

\subsubsection{La "normativa especial de protección de terrenos indígenas" en el sistema del Código Civil (1857 a 1927)}

Aunque se suele sindicar al modelo de propiedad inmobiliaria impuesto por el Código como el gran causante de los excesos que se cometieron, lo cierto es que desde el nacimiento de la república chilena se dictaron normas que posibilitaron abusos, al socavar la protección que el derecho indiano les dispensaba a los indígenas. Así, en 1819 Bernardo O'Higgins declaró a los indígenas libres, iguales y plenamente capaces, suprimiendo "por innecesario" el cargo de Protector de Naturales, que había cumplido una función eficaz de protección. Según Aldunate, “(...) esta medida fue el comienzo de una verdadera escalada de abusos, inmoralidades, expoliaciones y usurpaciones que llegaron a su máxima expresión con la ocupación de las tierras indígenas comenzada en la segunda década del siglo XIX" ${ }^{\prime \prime}$.

Sin perjuicio de lo anterior, indudablemente, con el Código Civil se introdujo un sistema que desconoció la particular concepción que los pueblos originarios tenían de la "propiedad". Y es que, como bien lo ha retratado Míguez, el Código Civil chileno además de favorecer la división de los terrenos (artículo 1317) declaró de patrimonio del Estado todas las tierras carentes de dueño o abandonadas (artículo 590), y estableció una jerarquía bajo cuyo peso la costumbre resultaba literalmente aplastada por el texto legal (artículo $2^{\circ}{ }^{10}$. En efecto, rompiendo con la tendencia del derecho indiano, el Código Civil solo reconoce la costumbre cuando la ley se remite expresamente a ella (secundum legem), repudiándola cuando es contraria y cuando estuviere en desuso. Según Guzmán, la razón de ello es que el derecho de los indígenas era un

\footnotetext{
${ }^{8}$ TAPIA (2005), pp. 174 y ss.

${ }^{9}$ ALDUNATE (1997), p. 120.

${ }^{10}$ MÍGUEZ (2013), p. 35.
} 
derecho especial y, como tal, no tenía cabida en un código de derecho común y general como es el civil”11.

Como se ve, la principal fuente de ordenación territorial de la naciente república desconoció las particularidades normativas que los indígenas pudiesen tener al excluir la costumbre. Paradójicamente, también de este periodo vienen las primeras medidas protectoras que impedían o limitaban la libre circulación de los bienes que ordenaba el Código Civil. Así, por ejemplo, se prohibió (salvo autorización), la adquisición de tierras en territorios indígenas, la realización de contratos de arrendamiento, anticresis e hipotecas, y se dictaron normas que protegían al indígena de la disposición testamentaria de sus bienes ${ }^{12}$. Pero, como se verá, estas disposiciones no pasaban de ser declaraciones meramente formales y, por lo mismo, no pudieron evitar que la decisión política de "civilizar" el territorio avanzara inexorablemente en perjuicio de las posesiones mapuche.

En este contexto, una ley de 4 de diciembre de 1866 ordenó el reparto del territorio que había ocupado el pueblo mapuche, disponiendo tres categorías de propiedad territorial: la indígena, la privada y la fiscal. El gobierno, siguiendo la propuesta del coronel Saavedra, abrazó la corriente estatista de colonización: los terrenos al sur del Bío Bío fueron considerados fiscales, correspondiendo al Estado la labor de sacarlos a remate para su posterior ocupación por particulares ${ }^{13}$.

Para llevar a cabo el ideal "civilizatorio" del indígena que se imponía en la época, pero sobre todo- para complementar la estrategia territorial que le daría mayor eficacia a la operación colonizadora de la Araucanía que se inició en el último cuarto del siglo XIX, el Estado chileno ordenó la fundación de poblaciones de indios o reducciones. Mediante esta iniciativa se transformó una gran masa de mapuche seminómadas en mapuche sedentarios, al tiempo que una ley de 1883 puso en actividad la Comisión Radicadora de Indígenas, que entre 1884 y 1929 otorgó cerca de tres mil títulos de merced en las provincias de Arauco y Osorno, quedando prácticamente todo el resto del territorio (en tanto que "tierra de nadie") en manos del Estado ${ }^{14}$.

Los terrenos adjudicados eran, en principio, aquellos ocupados por los mapuche ancestralmente. Sin embargo, para la determinación de los terrenos que las familias poseían de forma permanente, la Comisión Radicadora frecuentemente consideró y estableció un área menor a la extensión utilizada por la ganadería itinerante, reduciéndose de esta forma el territorio ancestral. Adicionalmente, tratándose de lugares remotos, las autoridades tradicionales no estaban debidamente enteradas de lo que sucedía, por lo que la Comisión Radicadora demoró en llegar o simplemente nunca lo hizo, lo que produjo que parte de la tierra pasara a manos de particulares ${ }^{15}$.

Éstos y otros factores locales determinaron la reducción dramática de la tierra ancestral mapuche, cuyas posesiones abarcarían al final del periodo de radicación sólo el 6,39\% del territorio total comprendido entre las provincias de Arauco y Osorno, quedando las tierras inscritas generalmente bajo la forma jurídica de una comunidad de bienes (propiedad colectiva), puesto que los títulos estatales de propiedad, usualmente, se expidieron a nombre de comunidades indígenas ${ }^{16}$.

\subsubsection{La normativa "evolucionista": de comunidades indígenas a propietarios individuales (1927 a 1993)}

A partir del año 1927, la política legislativa cambió su orientación y propició decididamente la división de las comunidades indígenas. En este periodo, que se extenderá

\footnotetext{
${ }^{11}$ GUZMÁN (1987), p. 254.

12 TAPIA (2005), p. 175.

${ }^{13}$ TAPIA (2005), pp. 174 y ss.

${ }^{14}$ Sobre este tema véase: QUEZADA (1995), pp. 133 y ss.; GONZÁLEZ (1986), pp. 13 y ss.; CALBUCURA (2013), pp. 107 y ss.; y MíGUEZ (2013), pp. 35 y ss.

${ }^{15}$ MÍGUEZ (2013), p. 32.

${ }^{16}$ GONZÁLEZ (1986), p. 7.
} 
hasta la dictación de la actual Ley Indígena de 1993, la idea "evolucionista" que inspiró la legislación fue considerar la propiedad individual como la mejor manera que tenían los indígenas para progresar económicamente e integrarse a la sociedad chilena (Ley $\mathrm{N}^{\circ} 4.169$ de 1927; Decreto $N^{\circ} 4.111$ de 1931; Ley Nº 14.511 de 1961 y Ley 17.729 de 1972) ${ }^{17}$.

Contrariamente a lo que podría suponerse, la idea de que la permanencia en las reducciones condenaba a los indígenas a la marginalidad no fue impulsada solo desde los círculos intelectuales criollos. De hecho, la Ley de Divisiones de Comunidades Mapuche de 1927, fue redactada y defendida por un dirigente mapuche. Su redactor fue Manuel Manquilef, que en el año 1927 era diputado del Partido Liberal y presidente de la Sociedad Caupolicán Defensora de la Araucanía ${ }^{18}$.

Es en el contexto descrito en el que cobra sentido la llamada Ley de Propiedad Austral (DS $\mathrm{N}^{\circ} 1.600$ de 1931, hoy DL N 574 de 1974), que buscó revalidar antiguos títulos de particulares, sobre todo de tierras indígenas desde el río Malleco hacia el sur. Esta tendencia se reforzó en la década de 1970 con la implementación de la política neoliberal de división de las comunidades indígenas, realizada mediante los Decretos Ley $\mathrm{N}^{\circ} 2.658$ y $\mathrm{N}^{\circ} 2.570$ de 1979, que ordenaron la división a solicitud de cualquiera de los comuneros en base a las extensiones de las posesiones que tuviesen en ese momento ${ }^{19}$. Asimismo, las hijuelas resultantes de las divisiones de las comunidades debían inscribirse en el Registro de Propiedad del Conservador de Bienes Raíces y quedaban gobernadas para todos los efectos legales por las normas del Código Civil ${ }^{20}$.

Según cifras aportadas por González Cortez, solo en parte de este periodo, 1.739 reducciones fueron divididas, dando lugar a la formación de 48.346 hijuelas que, en régimen de Código Civil, quedaron dispuestas para ser transadas en el mercado de tierras ${ }^{21}$. Como se comprenderá sin esfuerzo, este hecho contribuyó de manera importante a que gran parte de la tierra que el Estado les había reconocido a los indígenas pasase luego a manos de población no indígena.

Así las cosas, en un periodo en el que se consolidaba la idea de una sola nación chilena, no hubo espacio ni tolerancia en la legislación para nada fuera de ese paradigma. El mito decimonónico del Estado unitario fue fortificado por la unidad regulatoria creada por el Código Civil, especialmente mediante su modelo liberal de propiedad inmobiliaria, donde la propiedad del derecho común jugó un rol insustituible en la fundación misma de la República chilena en los términos ideológicos en que fue concebida. Como expresa Míguez, “(...) en una estructura jurídica inspirada en el individualismo, convencida por el evolucionismo y destinada a desarrollar el liberalismo económico ordenado por el poder público, el espacio para las modalidades de tenencia territorial mapuche era nulo"22.

\subsection{La propiedad indígena en la Ley № 19.253: un nuevo tipo de propiedad y un posible hito en la concepción de una nueva república}

En el recuento normativo que se viene haciendo tiene una importancia radical la LDI de 1993 pues, con ella, inicia un periodo de recomposición de las relaciones del Estado con los pueblos indígenas. Adicionalmente, supone un cambio claro de la política asimilacionista que el Estado dirigió hacia el mundo indígena, por una política de reconocimiento de lo indígena.

\footnotetext{
${ }^{17}$ Un detallado recuento y análisis de la legislación de la época puede encontrarse en ORMEÑO Y OSSES (1972), pp. 15 y ss.

18 BENGOA (2000), p. 385; BENGOA (2002), p. 254; MíGUEZ (2013), p. 39.

${ }^{19}$ Los mencionados cuerpos normativos revirtieron el proceso de reforma agraria que habían avanzado las Leyes № 16.640 , de 1967 y № 17.729 , de 1972 .

${ }^{20}$ ALMONACID (2009), pp. 54 y ss.

${ }^{21}$ GONZÁLEZ (1986), p. 10.

22 MíGUEZ (2013), p. 39.
} 
Como se verá enseguida, desde el punto de vista del sistema de conceptos que rige la propiedad raíz en Chile, la nueva regulación supone un cambio de paradigma en tanto "reconoce" una nueva forma de propiedad. Si a lo anterior se suma el mandato legal de proteger y propender a la ampliación de las tierras indígenas (art. 1 inc. final LDI), se genera una tensión entre la nueva propiedad indígena y las propiedades regidas por el derecho común que se encuentren enclavadas en el espacio territorial demandado por el pueblo mapuche, que no tardará en generar importantes problemas jurídicos.

\subsection{1. "Tierra indígena": la concepción de la propiedad indígena en la Ley № 19.253}

La LDI define lo que ha de entenderse por tierras indígenas, estableciendo normas que constituyen un nuevo orden público de protección mediante la instauración de una serie de limitaciones a las facultades y atributos del dominio civil. Pero más allá de las referidas limitaciones, la particularidad de esta regulación reside en el hecho de que la ley hace primar a la costumbre indígena por sobre el derecho del Código Civil, cuando se trata de la división de las comunidades. $Y$ es esta forma de regulación sin precedentes en el ordenamiento jurídico del Chile republicano, la que permite afirmar que se ha instituido un "nuevo tipo de propiedad" en el derecho patrio ${ }^{23}$.

Con respecto a la definición, en el artículo 12 la LDI consigna que son tierras indígenas: i) aquellas que actualmente se ocupan en propiedad o posesión proveniente de algunos de los títulos establecidos por ley; ii) aquellas que históricamente han ocupado y poseen las personas o comunidades indígenas ${ }^{24}$, siempre que se encuentren inscritas en el Registro de Tierras Indígenas; iii) aquellas que proviniendo de alguno de los títulos o modos anteriores sea declarada como tal por los Tribunales de Justicia; y iv) las recibidas por personas o comunidades indígenas a título gratuito del Estado ${ }^{25}$.

Como se puede apreciar, el estatuto legal hace constante referencia al reconocimiento estatal de las posesiones a la hora de clasificar la propiedad como indígena ${ }^{26}$. Adicionalmente, para que se acredite la naturaleza indígena de la propiedad, el artículo 15 exige que se encuentre inscrita en el Registro Público de Tierras Indígenas que está a cargo de la CONADI.

En lo que dice relación con el poder de disposición del titular del derecho de propiedad, la LDI impone limitaciones generales, así como limitaciones particulares respecto de tierras cuyos titulares sean comunidades indígenas. Respecto de los límites generales (los que afectan a cualquier tipo de titular), el art. 13 establece que las propiedades indígenas “(...) no podrán ser enajenadas, embargadas, gravadas, ni adquiridas por prescripción, salvo entre comunidades o personas indígenas de una misma etnia". La norma no solo excluye la posibilidad de que adquieran tierras indígenas personas naturales o jurídicas que no sean indígenas, sino que excluye también que otros indígenas que no formen parte de la misma etnia lo hagan. Respecto de los límites particulares, se ordena que las tierras cuyos titulares sean comunidades indígenas, tampoco “(...) podrán ser arrendadas, dadas en comodato, ni cedidas a terceros en uso, goce o administración". En términos generales, se puede decir que esta regulación surge como una reacción en contra de los históricos arrendamientos a 99 años, mediante los cuales la tierra indígena pasaba a manos de personas no indígenas.

Respecto del que quizás sea el problema jurídico más discutido en torno a la propiedad indígena durante el siglo XX y lo que va del $\left.X X\right|^{27}$, la LDI dispone una norma protectora. Según el artículo 16 , la división de tierras comunes debe solicitarse por la mayoría absoluta de sus

\footnotetext{
${ }^{23}$ Sobre las formas de propiedad y sus limitaciones: TAPIA (2005), pp. 167-168; PEÑAILILLO (2019), pp. 398 y ss.; VARAS (2003), pp. 143 y ss.; y VARAS (2007), pp. 255 y ss.

${ }^{24}$ La ley señala a los mapuches, aimaras, rapa nui o pascuenses, atacameñas, quechuas, collas, kawashkar y yámana.

${ }^{25}$ Con respecto a esta normativa la Corte Suprema ha sostenido en diversos fallos que la ocupación actual exige que las tierras objetos de los litigios "hayan estado ocupadas en propiedad o posesión por personas o comunidades indígenas al momento de entrada en vigor de dicha ley (Ley 19.253 de 1993)". Corte Suprema, Rol № 36.728-2015, de 4 de abril de 2016, considerando 1 ㅇ․

${ }^{26}$ AYLWIN (2005), pp. 5-6.

${ }^{27}$ Respecto de esta afirmación puede verse: WORTHEN (1998), pp. 250 y ss.; MíGUEZ (2013), pp. 39 y ss.
} 
titulares (salvo casos calificados) y el juez deberá efectuar la subdivisión de acuerdo con el derecho consuetudinario de la etnia y, solo en subsidio, se aplicará la regla del derecho común (art. 1317 del CC.). Como ya se adelantó, al establecer la preferencia por la costumbre indígena frente al Código Civil, puede decirse (en términos conceptuales) que la LDI realiza una verdadera derogación de la normativa del Código Civil, rompiendo la unidad regulativa de la propiedad en el ordenamiento republicano chileno, que hasta ese momento había sido sostenida por el Código ${ }^{28}$.

Por cierto que la convivencia de los dos modelos de propiedad genera una tensión que se reflejará en la dificultad de determinar qué tierras entran en uno u otro sistema, así como problemas de interpretación respecto de los mecanismos válidos para que las tierras indígenas puedan ser desafectadas ${ }^{29}$. Adicionalmente, la lectura de la regulación de la propiedad indígena a la luz del derecho internacional, generará nuevos focos de tensión, en tanto que demandará una flexibilización de las facultades del dominio de los predios de propiedad civil que se encuentren enclavados en "territorio indígena".

\subsection{2. "Tierra indígena" y "territorios indígenas": el estatuto territorial indígena a la luz del marco normativo internacional}

Cuando se habla de "territorios indígenas" en contraposición a "tierra indígena", se está designando una realidad que comprende tanto las tierras en posesión de personas indígenas que regula la Ley № 19.253 (individuales o colectivas), como los espacios territoriales que utilizan de "alguna otra manera", y de los recursos naturales presentes en ellos ${ }^{30}$. Ya se habrá advertido que la LDI no menciona el término "territorio indígena". Pero ello, lejos de resultar extraño, es simplemente la consecuencia lógica del desarrollo de un ordenamiento que no reconoce a los pueblos indígenas como sujetos colectivos preexistentes a la república, ni como sujetos colectivos titulares de derechos especiales ${ }^{31}$.

No obstante lo anterior, un análisis del texto de la LDI desde la perspectiva del marco normativo internacional que rige la materia (vía artículo 50 de la CPR) y de la jurisprudencia de la Corte Interamericana de Derechos Humanos (CIDH), lleva a dar por incorporado el concepto de "territorio indígena" y obliga a hacer esfuerzos conceptuales para adaptar el ordenamiento jurídico chileno a la nueva noción. Como se sabe, Chile ratificó el Convenio 169 sobre Pueblos Indígenas y Tribales en Países Independientes en el año $2008^{32}$. El convenio reconoce "(...) la importancia especial que para las culturas y valores espirituales de los pueblos interesados reviste su relación con las tierras o territorios, o con ambos, según los casos, que ocupan o utilizan de alguna otra manera, y en particular los aspectos colectivos de esa relación" (art. 13) ${ }^{33}$. En el mismo sentido, según su artículo 13 № 2, "la utilización del término "tierras" en los

\footnotetext{
${ }^{28}$ Por cierto que con posterioridad a la LDI de 1993 otros textos normativos como el Convenio 169, que se incorporó al derecho interno en el año 2009, vinieron a fortalecer el nuevo modelo de propiedad. Sin embargo, es necesario que insistamos en la enorme importancia conceptual que tiene la LDI por cuento, además de las muchas normas que le dedica a la propiedad indígena, se puede decir que le devuelve parte de la "soberanía" a los pueblos indígenas, al obligar a los jueces civiles a que apliquen el derecho de la etnia (la costumbre) con preferencia al del Código Civil. De esta manera, Chile vuelve a la tradición del Derecho Indiano que se vio interrumpida con la dictación del Código y la imposición de su modelo unitario de propiedad. Sobre la costumbre en las codificaciones civiles puede verse: GUZMAN (1987), p. 254.

${ }^{29}$ La noción de "desafectación de tierras" se encuentra referida en el artículo 13 inciso 3o de la LDI, cuando se regula la permutación de tierra indígena por tierra no indígena.

${ }^{30}$ Sobre la diferencia entre los conceptos tierra, territorio y recursos naturales: MEZA-LOPEHANDÍA (2013a), pp. 491 y ss.

31 MESA-LOPEHANDÍA (2016), p. 2. Algunos constitucionalistas han intentado asimilar a los pueblos indígenas a la categoría constitucional de los "grupos intermedios", se tratarían como entidades colectivas con cierta permanencia, que actúan en el seno del estado. SILVA (1997), pp. 50 y ss.

32 Según MESA-LOPEHANDÍA (2016), p. 3, cabe tener presente que el derecho internacional de los derechos humanos aplicable a los pueblos indígenas, no se agota en el citado Convenio. Por el contrario, tratados internacionales vigentes y ratificados por Chile, como la Convención Americana de Derechos Humanos y la Convención para la Eliminación de la Discriminación Racial, han sido interpretados por sus organismos de control, en el sentido de reconocer derechos territoriales a los pueblos indígenas. Confróntese también MEZALOPEHANDÍA (2013a), p. 416. Un estudio de los límites de la propiedad indígena en la jurisprudencia de la Corte Interamericana de Derechos Humanos puede verse en POBLETE (2018), pp. 69 y ss.

${ }^{33}$ Sobre la importancia de la tierra en la cosmovisión indígena y su reconocimiento constitucional AGUILAR (2010), p. 44 y ss.
} 
artículos 15 y 16 deberá incluir el concepto de territorios, lo que cubre la totalidad del hábitat de las regiones que los pueblos interesados ocupan o utilizan de alguna otra manera" ${ }^{34}$.

Adviértase, que la norma no se refiere a las tierras poseídas y ocupadas conforme a la regulación interna de los estados, sino que a aquellas tierras que utilizan conforme a sus "propias costumbres" ${ }^{35}$. En consecuencia, cuando el Convenio 169 se refiere al deber de reconocer el derecho de propiedad y posesión sobre sus tierras tradicionales, incluye los derechos que les correspondan sobre tierras que no estén ocupadas exclusiva y permanentemente por ellos, pero a las que hayan tenido acceso para realizar sus actividades tradicionales ${ }^{36}$. Si se acepta que el Convenio 169 es derecho chileno vigente, se tendrá que admitir que el concepto de "territorio indígena" también forma parte del ordenamiento jurídico chileno.

Por cierto, que el Convenio 169 es el fundamento normativo que ha utilizado la Corte Interamericana de Derechos Humanos (Corte IDH) para extender el ámbito de protección del derecho de propiedad indígena a terrenos que el derecho interno de los diferentes estados suele desconocer. Según la Corte, "al desconocerse el derecho ancestral de las comunidades indígenas sobre sus territorios, se podría afectar otros derechos básicos, como el derecho a la identidad cultural y a la supervivencia de las comunidades indígenas y sus miembros" ${ }^{37}$. En este sentido, la Corte IDH sostuvo en el caso Comunidad Sawhoyamaxa vs. Paraguay 2007 que negar la protección a las formas de propiedad indígena "equivaldría a sostener que sólo existe una forma de usar y disponer de los bienes, lo que a su vez significa hacer ilusoria la protección del artículo 21 de la Convención" ${ }^{38}$. De ahí que la protección de "la posesión tradicional de los indígenas sobre sus tierras tiene efectos equivalentes al título de pleno de dominio que otorga el Estado" 39 .

En lo que aquí interesa, es fácil advertir que el acceso a determinados predios a los que habilita la noción de territorio indígena (p. e., los de valor simbólico) no se ajusta con facilidad al ejercicio de los atributos del dominio de propiedades no indígenas que se ubican dentro de él, generando un nuevo polo de tensión. $Y$ aunque, por razones de espacio, no podemos ocuparnos aquí de los problemas jurídicos y políticos que a este polo se asocian, es necesario advertir que la armonización de las nociones referidas requiere revisar la noción de propiedad $\mathrm{civil}^{40}$. Y es en este contexto que podríamos preguntarnos si no podría ser vista la propiedad indígena como una de las piezas fundacionales de una nueva república chilena: una noción social de la propiedad para una república plurinacional ${ }^{41}$.

\section{Problemas de eficacia en torno a actos y contratos sobre propiedad indígena que exteriorizan la tensión entre los dos modelos de propiedad que conviven en Chile: las soluciones de la jurisprudencia judicial y administrativa}

Ya hemos visto como la LDI, además de redefinir la noción de tierra indígena que el ordenamiento jurídico chileno tenía, introdujo un orden público de protección de esta propiedad. En el diseño de la ley, esa protección se articula - básicamente-, estableciendo una serie de limitaciones a la facultad de disposición de los propietarios de tierras indígena, mediante la prohibición de que se realicen determinados contratos con personas no indígenas.

Por cierto que la transgresión de esas normas que introducen prohibiciones traerán consigo la ineficacia de los respectivos contratos. Pero, en adición a ello, es razonable pensar

\footnotetext{
${ }^{34}$ Sobre el convenio puede verse, MEZA-LOPEHANDÍA (2013b), pp. 337 y ss.; MEZA-LOPEHANDÍA (2016), p. 3; y ROJAS (2014), pp. 3850 .

35 Una revisión completa de los denominados títulos indígenas, y su diferencia con los títulos otorgados por el estado puede verse en AGUILAR (2005), pp. 269 y ss.

${ }^{36}$ Así lo señala el artículo 14 № 1 del Convenio 169 de la OIT. MEZA-LOPEHANDÍA (2016), p. 4.

${ }^{37}$ Yake Axa vs. Paraguay (2005), párrafo 147.

${ }^{38}$ Comunidad Indígena Sawhoyamaxa vs. Paraguay (2006), párrafo 120.

${ }^{39}$ Comunidad Indígena Sawhoyamaxa vs. Paraguay (2006), párrafo 128.

${ }^{40}$ Para una propuesta de solución desde los instrumentos de planificación territorial BALBONTíN-GALLO (2019), pp. 417 y ss.

${ }^{41}$ Es en este sentido que, en medio del actual debate constitucional, se ha indicado que la propiedad tiene un carácter multiforme, en clara referencia al reconocimiento constitucional de la propiedad indígena. RUIZ-TAGLE (2018), pp. 228-229.
} 
que la operación de un orden público de protección, conservación e -incluso-, ampliación de tierras indígenas, afectará la eficacia de actos y negocios no expresamente regulados en la legislación especial.

En lo que sigue se analizarán los problemas que está generando la aplicación de ese orden público de protección, a efectos de ir descubriendo las reglas de la experiencia práctica que, necesariamente, irán perfilando y completando el sistema normativo de la propiedad indígena en Chile.

\subsection{El régimen de nulidad vinculado a la transgresión de las reglas protectoras de la tierra indígena que introdujo la LDI}

Como ya se analizó, con la intención de proteger la propiedad indígena el legislador estableció una serie de reglas especiales y limitaciones a las facultades de disposición de los propietarios, al tiempo que dispuso la nulidad absoluta para el caso en que se transgredieran dichas limitaciones (artículos 13 y 14). Respecto de tal régimen de nulidad (nulidad absoluta), en la jurisprudencia de los tribunales se han discutido al menos dos importantes problemas: un primer asunto, tiene que ver con la identificación de los tipos de actos o contratos que se pueden anular invocando la LDI; y, un segundo problema, dice relación con la forma en que debe manifestarse el vicio en el acto y/o contrato a efectos de que el juez pueda declarar la nulidad de oficio.

Respecto del primer problema, ya hemos visto que la LDI prohíbe que se realicen determinados tipos de actos y contratos sobre tierra indígena. $Y$ aunque, desde la lógica de las reglas generales de interpretación, podría pensarse que solo están prohibidos los actos y contratos expresamente mencionados ${ }^{42}$, el hecho de que estemos ante un orden público de protección permite plantear la duda. En la jurisprudencia el tema no ha sido muy discutido, pero al menos en una ocasión los tribunales anularon un contrato sobre tierra indígena cuya celebración no se encuentra expresamente prohibida por la ley.

En efecto, en Bravo Cayuñanco con Constructora Morales y Hermanos Ltda ${ }^{43}$ la Corte Suprema anuló la cesión de un contrato de arrendamiento sobre tierra indígena ${ }^{44}$. En el caso, el arrendatario de una tierra indígena cedió su calidad a la Constructora Morales Hermanos Ltda. por la suma única de $\$ 20.000 .000$, y por todo el tiempo de arriendo que le restaba (72 años). Al enterarse de ese negocio, los herederos de la arrendadora demandaron la nulidad absoluta de la cesión aduciendo que se trataba de tierra indígena. La demanda fue rechazada por los tribunales de instancia, pero la Corte Suprema casó el fallo de apelaciones y declaró la nulidad del negocio. La Corte estimó que la cláusula que facultaba al arrendatario a subarrendar o ceder el predio arrendado, no lo habilitaba a celebrar un "contrato de cesión que contraviene la política de interés nacional que dicha ley establece"; y a esa afirmación añadió, que "la conclusión contraria importaría desconocer el manifiesto interés legislativo por evitar que los indígenas pierdan sus tierras" ${ }^{45}$.

Como puede apreciarse, para la Corte Suprema es posible aplicar la sanción de nulidad absoluta contemplada en el artículo 13 de la LDI a casos no expresamente contemplados, si se estima que ese negocio contraviene la directriz política que la LDI ha dado. La decisión de la Corte se entiende mejor si se repara en el hecho de que el contrato de arrendamiento original se había celebrado entre una mujer indígena y una persona no indígena, en un periodo anterior a la LDI de 1993. Si a ello se suma el hecho de que en Bravo Cayuñanco con Tiznado ${ }^{46}$ se había rechazado una acción de nulidad sobre ese mismo arrendamiento ya estando vigente la LDI, y que el principal argumento esgrimido para su rechazo fue que la acción se encontraba prescrita

\footnotetext{
42 En este sentido RODRÍGUEZ (2019), párrafo 15.

${ }^{43}$ Corte Suprema, Rol № 89.636-2016, de 29 de noviembre de 2017.

${ }^{44}$ Este caso igualmente podría revisarse a propósito de aquellos casos que no se encuentran expresamente regulados, ya que la cesión no se encuentra entre los actos prohibidos por el artículo 13 de la LDI.

${ }^{45}$ Corte Suprema, Rol № 89.636-2016, de 29 de noviembre de 2017, considerando 70.

${ }^{46}$ Corte Suprema, Rol № 6.763-2009, de 17 de junio de 2011.
} 
(10 años), la solución de la Corte parece bastante razonable. Adicionalmente, las circunstancias que rodearon este caso permiten preguntarnos por la vigencia de la norma que ordenaba la imprescriptibilidad de la acción de nulidad (artículo 12 de la Ley № 17.729), en tanto que la LDI de 1993 nada dijo al respecto.

Respecto del segundo problema referido, debemos partir por precisar que las acciones de nulidad a instancia de parte no suelen prosperar respecto de los negocios sobre tierra indígena, en tanto que el artículo 1683 del Código Civil establece que esta acción solo puede ser alegada por quien tenga interés en ello, pero haciendo excepción del que ha ejecutado el acto o celebrado el contrato "sabiendo o debiendo saber el vicio que lo invalidaba". De ahí que cuando estos casos llegan a conocimiento de los jueces, la declaración de oficio de la nulidad es la vía que les queda para evitar la desafectación de la tierra indígena. Sin embargo, como la nulidad "puede y debe" ser declarada de oficio "cuando aparece de manifiesto en el acto o contrato, y en los contratos sobre tierra indígena normalmente se omite mencionar la calidad de la tierra, cabe preguntarse si le estaría permitido al juez advertir la nulidad de alguna otra forma.

La respuesta a esta pregunta no es uniforme en la jurisprudencia. En efecto, se pueden observar fallos que, aparentemente, sostienen la tesis de que al juez le está vedado recurrir a documentos para declarar la nulidad de oficio. Así, por ejemplo, se estimó en Coñuecar con Cabrera $^{47}$. En el caso, el juzgador consideró que el vicio de nulidad no es manifiesto si el tribunal debió recurrir a la inscripción registral de quien sucede el vendedor, para calificar el inmueble objeto de un contrato de compraventa como indígena. Sin perjuicio de lo anterior, existen otros fallos que se han pronunciado a favor de declarar la nulidad de oficio, si el vicio de nulidad queda de manifiesto mediante el informe que por mandato legal debe emitir la CONADI cuando, entre otras cosas, se discuta el dominio de tierras indígenas (artículo 56 LDI). Acorde con esta última línea argumental, en Huenul Huenul con Granzotto Brun ${ }^{48}$ la Corte Suprema declaró de oficio la nulidad absoluta de un contrato de compraventa de tierra indígena celebrado entre una persona indígena y otra no indígena, valiéndose de un informe de la CONADI que dejaba patente el vicio de nulidad del que adolecía el contrato bajo análisis.

\subsection{Regularización de la pequeña propiedad raíz (DL 2.695) en contexto de la Ley Indígena: tierra regularizada (sea o no indígena) por un indígena, será tierra indígena}

El D.L. 2695 es una normativa especial que regula el procedimiento administrativo mediante el cual un poseedor material de un inmueble se constituye en poseedor regular del mismo y, en consecuencia, queda habilitado para adquirir el dominio mediante el transcurso del especial plazo legal que se requiere para que opere la prescripción adquisitiva.

Debido a que se trata de un procedimiento que puede llevar a adquirir el dominio de un inmueble que pertenece a un tercero, respecto del tema que aquí se analiza, saltan a la vista al menos tres preguntas: en primer lugar, cabría preguntarse si se puede regularizar tierra indígena mediante el procedimiento regulado por el D.L. 2.695; en segundo lugar, y en caso de responder afirmativamente lo anterior, podríamos preguntarnos si una persona no indígena podría utilizar el referido procedimiento para regularizar tierra indígena; $y$, en tercer y último lugar, podríamos preguntarnos si la regularización de una tierra no indígena por una persona indígena, mediante el procedimiento de referencia, determina la calidad indígena de la tierra.

Respecto de la primera pregunta, esto es, si se puede utilizar el procedimiento contemplado por el D.L. 2695 para sanear la posesión de tierra indígena, la respuesta de los tribunales ha sido afirmativa. Aunque es difícil encontrar decisiones que se refieran directamente al punto, la intensa discusión que se generó en Moreno con Cheuquel ${ }^{49}$ permite

\footnotetext{
${ }^{47}$ Corte Suprema, Rol № 7168-2017, de 21 de junio de 2018.

${ }^{48}$ Corte Suprema, Rol № 6.570-2008, de 6 de diciembre de 2010. Pese a rechazar la nulidad de oficio, la corte acabo anulando el negocio al confirmar la sentencia de primera instancia que había acogido la demanda de nulidad absoluta a instancia de parte.

${ }^{49}$ Corte Suprema, Rol № 9581-2013, de 5 de mayo de 2014.
} 
extraer esa conclusión, al tiempo que sirve para perfilar otros extremos importantes del procedimiento aplicable.

En los hechos, el señor César Cheuquel tramitaba un procedimiento de regularización de un terreno que tenía la calidad de tierra indígena, en el que se presentó una oposición fundada en la falta de posesión material del inmueble (art. 2 del D.L. 2695). Al conocer del asunto, la Corte de Apelaciones de Temuco revocó el fallo de primera instancia y terminó ordenando la inscripción del inmueble a nombre del peticionario (Cheuquel), en base al artículo 24 del decreto. Sin embargo, la Corte Suprema anuló de oficio todo lo obrado al considerar que no se cumplió con la norma que ordena aplicar el procedimiento contemplado en el artículo 56 de la LDI, en la fase judicial de la oposición que contempla el D.L 2695.

Es muy interesante el fundamento del voto de minoría, que consideró aplicable el D.L. 2.695 para regularizar tierra indígena. Según la disidencia, el procedimiento del D.L. 2.695 sería aplicable en tanto que la LDI no contempla procedimientos especiales de saneamiento, y en cuanto permite expresamente la adquisición mediante prescripción adquisitiva del dominio cuando el asunto interesa a indígenas de la misma etnia (artículo 13). Si se mira con atención, la decisión y el voto de minoría coinciden en que se puede aplicar el D.L. 2.695 para regularizar tierra indígena $y$, únicamente, discrepan sobre el procedimiento aplicable a la fase judicial que contempla el D.L. 2.695 (fase de oposiciones). Y ello es importante, puesto que esa misma opinión ha sido sostenida recientemente por la Contraloría General de la República en un dictamen de 2019, en el que manifestó que "la adquisición de inmuebles por aplicación del procedimiento de regularización contemplado en el decreto ley № 2.695 de 1979, constituye adquisición por prescripción, ese se encuentra dentro de los supuestos del artículo 13, y, por ende, resulta posible aplicar dicho procedimiento entre comunidades o personas indígenas de una misma etnia" 50 .

Con todo lo expuesto, se puede afirmar que en Chile es posible regularizar tierra indígena mediante el procedimiento dispuesto por el D.L. 2.695, siempre y cuando quien esté regularizando sea una comunidad o una persona indígena de la misma etnia.

Respecto de la segunda pregunta, una interpretación orientada a la protección de la tierra indígena solo puede llevar a sotener, que el procedimiento de regularización de la pequeña propiedad raíz no puede ser utilizado para regularizar tierra indígena por una persona no indígena. Lo anterior fue sostenido por los tribunales de justicia chilenos en Namoncura con Araneda y otro ${ }^{51}$. En los hechos, el señor Araneda (persona no indígena) había conseguido inscribir la resolución del Ministerio de Bienes Nacionales que le reconocía la calidad de poseedor regular de un terreno mediante el procedimiento del D.L. 2.695. Debido a que el terreno se superponía parcialmente con otro predio que tenía la calidad de tierra indígena, el dueño del predio colindante (señor Namoncura) demandó la nulidad del procedimiento administrativo de regularización.

Conociendo del caso, el Juzgado de Letras de Cañete consideró que el procedimiento del D.L. 2.695 no era adecuado para que una persona no indígena regularizara tierra indígena y, en consecuencia, declaró la nulidad del mismo. Según el juzgador, el artículo 8 del D.L. 2.695, hace inaplicable el procedimiento de regularización a aquellas tierras declaradas indígenas por la Ley № $17.729^{52}$. Adicionalmente, el fallo que luego fue confirmado por la Corte de Apelaciones de Concepción y por la Corte Suprema, sostuvo que la LDI prohíbe expresamente que personas no indígenas adquieran tierra indígena mediante prescripción adquisitiva, por lo que mal podría entenderse aplicable el D.L. 2.695.

Por lo anterior, y no obstante que son pocos los casos, se puede afirmar que existe una tendencia en la jurisprudencia que impide utilizar el procedimiento de referencia para regularizar tierra indígena a personas ajenas a la etnia. Si lo que se quiere es conservar las tierras

\footnotetext{
${ }^{50}$ Contraloría General de la República, Dictamen № 010544N19, de 16 de abril de 2019.

${ }^{51}$ Corte Suprema, Rol № 19.268-2018, de 6 de abril de 2020.

52 Juzgado de Letras de Cañete, Rol C-90-2015, de 14 de agosto de 2017. En este punto es importante mencionar, que el D.L. 2.695 hace referencia a la ley 17.729 , por lo que el tribunal de primera instancia consideró que como dicha ley fue derogada orgánicamente por la LDI, se debe entender que esta prohibición hace referencia a las tierras consideradas indígenas por la ley № 19.253 .
} 
indígenas en manos indígenas, las decisiones judiciales analizadas parecen ir en el sentido correcto.

En relación con la tercera pregunta, el artículo 12 letra d) de la LDI parece decir que todo inmueble regularizado por una persona indígena adquiere la calidad de tierra indígena. En la jurisprudencia de los tribunales, una afirmación igual puede observarse en Saavedra Huentelaf con Forestal Anchile $L t d a^{53}$. En el caso, se demandó la nulidad de una compraventa celebrada con una empresa forestal, toda vez que el inmueble objeto de la compraventa había sido adquirido por la solicitante mediante el procedimiento de regularización (D.L. 2.695) y, por lo tanto, tendría la calidad de tierra indígena. Al conocer el caso, la Corte Suprema rechazó el recurso de casación presentado por la demandada contra la sentencia de la Corte de Apelaciones de Valdivia, que confirmó sentencia de primera instancia que declaraba la nulidad del contrato de compraventa. La Corte, a pesar de haber rechazado el recurso por razones formales, se pronunció sobre la calidad de la tierra objeto del contrato, considerando que "de la norma transcrita se desprende indefectiblemente, en cuanto importa al caso en estudio, que la ley le ha asignado la calidad de tierras indígenas, entre otras, a aquellas que ocupan personas indígenas en dominio que ha derivado de un título otorgado de acuerdo al Decreto Ley 2.695, situación en la cual precisamente se encuentra la actora ${ }^{54}$.

Por todo lo anterior, se puede afirmar que la mayoría de las interacciones posibles entre el D.L. 2.695 y la LDI se encuentran reguladas por alguno de estos dos cuerpos normativos. Y, en los casos no expresamente contemplados, tanto la jurisprudencia de nuestros tribunales como la jurisprudencia administrativa, se han inclinado por la interpretación que mantiene la tierra en manos de los indígenas.

\subsection{Otros casos no regulados: ¿Debe hacerse una interpretación que evite la desafectación de tierra indígena?}

Aparte de la hipótesis de desafectación de tierra indígena contemplada en la ley (permuta de tierras indígenas por tierras de no indígenas), pueden imaginarse otras en las que podría plantearse la posibilidad de que tierras indígenas pierdan esa calidad ${ }^{55}$. Como se trata de casos que no se encuentran expresamente contemplados, se presenta un interesante problema de interpretación que habrá que resolver, ponderando el principio de protección de la propiedad indígena con los principios de la autonomía de la voluntad y la libre circulación de los bienes que acompañan a la propiedad civil, para determinar la eficacia del acto o negocio del que se trate. Al menos dos casos que han sido (o están siendo) conocidos por los tribunales de justicia sirven para ilustrar la orientación de la jurisprudencia nacional sobre estos asuntos.

El primer caso, dice relación con la impugnación de la compraventa de un terreno indígena, tuvo una importante repercusión mediática en tanto que tiene al ex subsecretario del Ministerio del Interior, señor Rodrigo Ubilla, como una de las partes en conflicto. En los hechos, el señor Jorge Painequir Molina adquirió por medio de una compraventa fiduciaria celebrada con Romualdo Painequir (su padre), el Lote identificado como 127-B1. El terreno le había sido adjudicado a su padre al momento de liquidarse la Comunidad Indígena Mariano Millahual. Pero en ese momento, don Jorge Painequir se encontraba casado bajo el régimen patrimonial de sociedad conyugal con Guadalupe Moris, una mujer no indígena. Años después, los cónyuges deciden cambiar el régimen patrimonial del matrimonio, lo que trajo como consecuencia la liquidación de la sociedad conyugal y la posterior adjudicación de parte del Lote 127-B1 a Guadalupe Moris. Ya siendo Guadalupe la dueña de una parte del lote, éste se subdivide en tres lotes de $5.000 \mathrm{mts} 2$ cada uno, que son vendidos al ex subsecretario (quien los aportó a una sociedad de responsabilidad limitada que formó con su familia).

53 Corte Suprema, Rol № 4.384-2007, de 11 de diciembre de 2008.

${ }^{54}$ Corte Suprema, Rol № 4.384-2007, de 11 de diciembre de 2008, considerando 6ㅇ.

${ }^{55}$ Aparte del caso referido en el apartado anterior, piénsese, por ejemplo, en la herencia vacante de un propietario de tierra indígena ¿Es posible que, tras la declaración de vacancia, la tierra indígena sea adquirida por el Fisco? 
El problema jurídico que plantea este caso consiste en determinar si una propiedad inscrita como indígena que forma parte de una sociedad conyugal, puede ser adjudicada al cónyuge no indígena al liquidarse la sociedad: ¿es esta una vía de desafectación de tierra indígena no contemplada en la ley? Al resolver el litigio, el juez del Juzgado de Letras y Garantía de Pucón respondió esa pregunta considerando que las tierras objeto de la compraventa celebrada por Ubilla sí tienen la calificación de indígenas, dado que la liquidación de la sociedad conyugal y posterior adjudicación a un no indígena no desafecta la propiedad de su carácter de indígena ${ }^{56}$. No obstante lo anterior, termina rechazando la acción al considerar que los demandantes carecían de legitimación activa y, que al juez le está vedado anular de oficio si el vicio no aparece de manifiesto en el contrato ${ }^{57}$.

Pero más allá de la nulidad de la compraventa, la solución del caso permite suponer que la inscripción de la propiedad a nombre de la señora Moris, también adolece de un vicio de nulidad y que, por lo tanto, el cónyuge no indígena no puede adquirir ningún derecho sobre tierras indígenas debido a la liquidación de la sociedad conyugal.

Un segundo caso que reviste interés en lo que dice relación con la desafectación de tierras indígenas lo constituye Paillalef con Conadi. En los hechos, en el contexto de una venta de un terreno ubicado en la localidad de Carileufu de la ciudad de Pucón, que había sido adquirido en el año 2014 por la señora Teresa Paillalef mediante sucesión hereditaria, se consultó a la CONADI por la calidad del terreno. Mediante certificado emitido por la encargada del Registro Público de Tierras Indígenas se informó que el inmueble había sido incluido dentro del registro en el año 2015.

Contra esta resolución la señora Paillalef interpuso un recurso de protección que, en lo medular, se fundamentó en que la incorporación del inmueble al registro suponía una vulneración al derecho de propiedad al impedir la libre disposición del inmueble. Según la recurrente, el bien raíz no sería indígena (no obstante tener como antecedente un título de merced) en tanto que el titulo inmediatamente anterior al suyo se habría obtenido mediante una sucesión hereditaria, pero en una época en la que aún no se encontraba vigente la LDI y que, por lo mismo, era una propiedad individual que se regía por las normas de Código Civil.

El problema jurídico consiste es determinar si las propiedades que tienen como antecedente un título de merced (o similar) y que actualmente están en manos de indígenas, pueden ser consideradas propiedad civil en caso de haber adquirido tal calidad por la aplicación de una ley anterior a la LDI. El problema así planteado reviste un especial interés pues, como se analizó brevemente al inicio de este trabajo, la normativa "evolucionista" que se dictó a partir del segundo cuarto de siglo XX promovió el establecimiento de la propiedad civil al facilitar, normativamente hablando, la división de las comunidades.

Al resolver el recurso, la Corte de Apelaciones de Temuco consideró que "proviniendo el inmueble de la recurrente de subdivisiones y adjudicaciones de un terreno de mayor extensión otorgado por un título de merced, no se advierte ilegalidad ni arbitrariedad alguna por parte de los recurridos al efectuar la inscripción de dicha propiedad en el Registro Público de Tierras Indígenas". Aunque la Corte dejó abierta la posibilidad de que en un juicio de lato conocimiento se pueda determinar si las adjudicaciones de las que fue objeto el inmueble en cuestión le han hecho perder su calidad de tierra indígena, parece - prima facie-, negar la posibilidad de desafectar un terreno indígena utilizando la argumentación esgrimida por la recurrente ${ }^{58}$.

Así las cosas, y pese a que la jurisprudencia es aún escasa, se puede afirmar que hay una tendencia a restringir cualquier posibilidad de que se desafecte tierra indígena fuera del caso de la permuta contemplado en el artículo 13 de la LDI. Y es en esta línea de argumentación, que la

\footnotetext{
${ }^{56}$ Véase considerando 14ㅇs sentencia Juzgado de Letras y Garantía de Pucón, Rol № 162-2019, de 21 de enero de 2020.

${ }^{57}$ Este caso es distinto a los que se revisaron en el primer apartado toda vez que, en aquellos el informe de la CONADI calificaba las tierras como indígena. Aunque resulta muy cuestionable a la luz del derecho vigente, en el caso que revisamos el informe de la CONADI, consideró que por vía de adjudicación el inmueble había perdido su calidad de tierra indígena.

${ }^{58}$ Corte de Apelaciones de Temuco, Rol № 4.934-2015, de 1 de febrero de 2016. El fallo fue confirmado por Corte Suprema, Rol № 16.063-2016, de 30 de marzo de 2016. Comentando dicho fallo indica Beca que la afectación al derecho de propiedad se encontraría amparada en la función social del derecho de propiedad. BECA (2020), pp. 399-400.
} 
Corte de Apelaciones de Temuco dejó dicho, en un caso en que se discutía la interpretación de otra de las normas que podrían llevar a la desafectación de tierra indígena (art. 17 inc. 2 LDI), que "el legislador sólo contempló expresamente el mecanismo de desafección de la calidad de tierra indígena para el caso de las autorizaciones de permutas de tierra indígena por una no indígena" ${ }^{59}$.

Por lo anterior, ante los casos no regulados, parece razonable optar por la interpretación que evita la desafectación de tierra indígena. Y es que, si se comparte la idea de que el legislador chileno incorporó un orden público de protección de la cosmovisión indígena que se articula fundamentalmente sobre la protección de la tenencia de la tierra, la solución no puede ser otra.

\subsection{Problemas de aplicación de la LDI en el tiempo: ¿Una excepción al principio de irretroactividad de la ley?}

Como se ha visto, la LDI de 1993 derogó expresa y orgánicamente la anterior ley indígena (№ 17.729), modificando varias de las normas que tenían como objetivo proteger la tierra indígena (art. 78). La nueva ley amplió el catálogo de actos y contratos que no se pueden celebrar con terceros ajenos a la etnia y, aunque continuó permitiendo ciertos contratos como los de arrendamiento, prescribió que estos no podían hacerse por un plazo superior a cinco años. Por lo anterior, han surgido problemas, por un lado, con la eficacia de la promesa de ciertos contratos y con la validez de ciertos gravámenes que estaban permitidos bajo el régimen de la antigua ley, y que se encuentran prohibidos bajo el régimen de la vigente; y por otro, con los contratos de arrendamiento celebrados al amparo de la antigua ley, pero con un plazo que excede los 5 años que contempla la nueva.

Respecto a los casos de los gravámenes constituidos con anterioridad a la entrada en vigor de la LDI la jurisprudencia es muy escasa. Sin embargo, en Véjar Reliqueo con Banco del Estado los tribunales consideraron válida la realización de estos gravámenes, ya vigente la LDI, no obstante que ello implicaba una desafectación de tierra indígena. En el caso, se demandó la nulidad de una adjudicación en pública subasta de un inmueble que tenía la calidad de indígena, pero que había sido gravado con una hipoteca constituida al amparo de la Ley № 17.729. Conociendo del recurso de casación la Corte Suprema confirmó los fallos de instancia y rechazó la posibilidad de anular el contrato afirmando que “(...) si la Ley № 17.729 autorizaba a otorgar en hipoteca a favor del Banco del Estado de Chile un inmueble indígena, el derecho así constituido debe ser mantenido aún bajo la aplicación de lo preceptuado por la Ley № 19.253, publicada en el Diario Oficial de 5 de Octubre de 1993, por cuanto corresponde, para todo efecto futuro, a un derecho adquirido, debiendo ser respetado y mantenido, no obstante los posteriores designios legislativos" 60 .

El razonamiento de la Corte pasa por alto que la hipoteca es un derecho real y que, por lo mismo, le es aplicable el artículo 12 de la Ley de Efecto Retroactivo de las Leyes (LERL). Dicha disposición indica que los derechos reales subsisten cuando se dicte una nueva ley pero que, en lo referido a goces, cargas y extinción, prevalecerán las disposiciones de la nueva ley. Así, el problema de retroactividad en el caso de derechos reales como la hipoteca tiene una solución expresa en el caso que nos ocupa, debiendo extinguirse el derecho real desde que el artículo 13 de la LDI prohíbe que las tierras sean gravadas.

Respecto de las promesas de contratos celebradas bajo la antigua ley sobre inmuebles indígenas cuya enajenación se encuentra actualmente prohibida, la jurisprudencia ha dicho que son inválidas. Como se sabe, la antigua ley indígena (№ 17.729) permitía la transferencia de tierra indígena a personas no indígenas, transcurrido un plazo de 20 años. De allí que una práctica habitual para desafectar tierra indígena era celebrar arrendamientos a 20 años, acompañados de una promesa de compraventa. Por lo mismo el problema jurídico consiste en

\footnotetext{
${ }^{59}$ Corte de Apelaciones de Temuco, Rol № 1.167-2012, de 10 de septiembre de 2012, considerando 5ㅇ.

${ }^{60}$ Corte Suprema, Rol № 5570-2013, de 23 de julio de 2014, considerando 8; con voto en contra que estuvo por acoger la nulidad de la adjudicación.
} 
determinar la validez de esas promesas, desde que entró en vigor la LDI, que prohíbe toda enajenación.

En la jurisprudencia, la invalidez de las promesas se justificó aduciendo que el contrato prometido debe ser válido para que la promesa tenga efectos (artículo 1554 № 2). Una solución como la referida puede verse en Collilef Millar con Peña Sobarzo ${ }^{61}$, caso en el que se demandó la nulidad de una promesa de compraventa suscrita en 1987. En lo que aquí interesa, en contra de la sentencia que anuló la promesa, se interpuso un recurso de casación fundado en la infracción a las normas de efecto retroactivo de las leyes (artículo 22 LERL). Conociendo del recurso, la Corte dejó sentado que la nulidad no obedece a la aplicación retroactiva de la LDI, sino a la operación del artículo 1554 № 2 del Código Civil, que prescribe la nulidad de la promesa cuando el contrato prometido es ineficaz según la normativa vigente.

Por último, con respecto a la validez o eficacia de los contratos de arrendamientos con plazo superior a 5 años que se celebraron con anterioridad a la entrada en vigor de la LDI, la jurisprudencia se ha decantado por privarlos de efectos ${ }^{62}$ aunque, ante la defensa basada en el principio de irretroactividad de la ley, su argumentación parece presuponer que la celebración de los contratos de arrendamiento fue hecha en fraude a la ley. La posición de la Corte Suprema puede verse con toda claridad en la sentencia que, recientemente, resolvió el caso Huilipan Marfilio con Toro Villagrán.

En el caso, se demandó la terminación de un contrato de arrendamiento por parte del arrendador, fundado en que el plazo de duración excedía el límite de 5 años (la duración pactada originalmente era de 99 años). La demanda fue rechazada en primera y en segunda instancia, bajo el argumento de que el contrato de arrendamiento se celebró bajo la vigencia de una ley que lo permitía. Sin embargo, conociendo del recurso de casación, la Corte Suprema revocó el fallo y dio por terminado el contrato de arrendamiento considerando, en lo que aquí interesa, que dichos arrendamientos funcionaban como una forma de encubrir la enajenación prohibida por la Ley 17.729. Así, al tratarse de un contrato otorgado en fraude a la ley y, considerando que ni el artículo 9 del Código Civil ni el artículo 22 de la LERL constituyen elementos que impidan la terminación del arrendamiento, sostuvo que "en este caso específico, a través de la aplicación de la nueva Ley 19.253 a la postre no se está sino restableciendo el imperio de lo dispuesto en la ley vigente al momento de la celebración del contrato, utilizado, presumiblemente -como se explicó- para cometer un fraude a la ley, lo que, a la luz de las normas actualmente vigentes no resulta tolerable, dada la importancia nacional que el legislador otorgó a la protección de las tierras indígenas" ${ }^{63}$.

Al parecer, en lugar de efectuar una aplicación retroactiva de la LDI que llevaría consigo la nulidad de estos arrendamientos, la Corte parece estar aplicando la Ley 17.729 al aceptar la terminación del contrato de arrendamiento a 99 años con canon único (considerando sexto), bajo el entendimiento de que estas formas de arrendamiento llevan consigo un principio de enajenación y, por lo mismo, un fraude tanto a la Ley 17.729 como a la actual LDI. Por lo anterior, queda viva la pregunta sobre la eficacia de arriendos que se hayan constituido al amparo de la Ley № 17.729 , con un plazo razonable y con un canon arrendaticio acorde al precio de mercado. No dándose los presupuestos del fraude a la ley, difícilmente se podrían dar por terminados; y dado que los contratos de arrendamiento generan derechos personales, parece que el principio de irretroactividad de la ley dificultaría anular estos contratos, no obstante superar el plazo de 5 años que dispuso la LDI.

\footnotetext{
${ }^{61}$ Corte Suprema, Rol № 8.228-2010, de 9 de enero de 2013, considerando 16ㅇ. En un sentido similar Corte Suprema, Rol № 6.5702008, de 6 de diciembre de 2010; Corte Suprema, Rol № 4.897-2007, de 15 de octubre de 2008; y Corte Suprema, Rol № 7.421-2008, de 9 de noviembre de 2009.

${ }^{62}$ La misma sentencia del caso en comento hace referencia a las siguientes sentencias de la Corte Suprema: Rol № 5561-2008, de 8 de julio de 2010; Rol № 1903-2009, de 25 de enero de 2011, y Rol № 89.636-16, de 29 de noviembre de 2017.

${ }^{63}$ Corte Suprema, Rol № 23194-2018, de 3 de marzo de 2020, considerando 8‥ En este mismo sentido Corte de Apelaciones de Valdivia, Rol № 393-2020, de 24 de diciembre de 2020 (con recurso de casación pendiente).
} 


\subsection{Las facultades del Conservador respecto de la inscripción de títulos que podrían llevar a la desafectación de tierra indígena}

Así como se ha discutido las facultades de los jueces para anular de oficio los actos o contratos referentes a tierras indígenas, también se ha discutido en la jurisprudencia las facultades del Conservador de Bienes Raíces (artículo 13 del R) para negarse a inscribir, cuando el vicio no aparece de manifiesto en el título. No obstante que en la jurisprudencia se pueden encontrar algunos fallos restrictivos ${ }^{64}$, se observa una tendencia en orden a considerar que el Conservador sí puede negar la inscripción cuando se trata de títulos que puedan llevar a la desafectación de tierra indígena.

Así, por ejemplo, en Braun Hadida y otro, el CBR de Río Bueno se negó a inscribir una compraventa de tierra indígena que tenía como antecedente una promesa válida. La pretensión de que se ordenara al Conservador realizar la inscripción fue rechaza en primera y segunda instancia. Al conocer del caso, la Corte Suprema dejó sentado que el Conservador “(...) se ha ceñido a los principios que ordenan el ejercicio de su ministerio, el que, atendida su envergadura, debe ser desempeñado con absoluto celo" ${ }^{65}$. Misma lógica se aplica en el Rivera Muñoz ${ }^{66}$, caso en que la Corte confirmó el fallo de instancia que sostuvo que el CBR, en virtud del artículo 13 de su reglamento, tiene las facultades para pedir más antecedentes “(...) que permitan verificar si en la especie se cumple o no con la Ley, pues, se debe evitar que por medios de subterfugios legales, se obtenga la desafectación de un inmueble en clara vulneración a las disposiciones legales" ${ }^{\prime \prime}$.

Como se puede ver, tratándose de tierra indígena, la negativa del CBR a inscribir es avalada por la reciente jurisprudencia. La solución parece razonable, atendidas las reglas que regulan las facultades del CBR y el contexto normativo de protección en que se desarrolla la discusión.

Respecto de las reglas que regulan las facultades del CBR, y a pesar de que la discusión se ha planteado en términos análogos a las facultades anulatorias de oficio del juez, lo cierto es que el artículo 13 del reglamento faculta al CBR para negar la inscripción en varios otros supuestos, además de cuando el defecto de nulidad absoluta resulta visible en el título. En efecto, cuando la referida norma prescribe "deberá, no obstante, negarse, si la inscripción es en algún sentido legalmente inadmisible; por ejemplo (...)", parece razonable interpretar que el CBR pueda negar la inscripción (tratándose de tierra indígena), puesto que en estos casos la inscripción parece más que "en algún sentido legalmente inadmisible".

Para terminar este punto, no solo parece que el CBR tiene las facultades para negarse a realizar la inscripción, sino que respecto de títulos que puedan desafectar tierra indígena debe proceder con particular rigor y celo. Si se miran bien las cosas, en la práctica el CBR es el garante de la eficacia de todo el orden púbico de protección indígena. Esa es la solución a la que se arriba si se toman en cuenta los plazos y costos de litigación que exhibe la jurisdicción chilena; las particularidades sociológicas de los pueblos indígenas; y el hecho de que la posesión de la tierra está en la base de la cosmovisión indígena. Y es que, en el contexto descrito, no se puede menos que aceptar que si una tierra indígena es desafectada erróneamente, la posibilidad de que se pueda recuperar la misma es prácticamente nula.

\section{Conclusión}

1. La LDI reguló la propiedad sobre las tierras indígenas con tal grado de especificidad que se puede decir que se incorporó al ordenamiento jurídico chileno un nuevo

\footnotetext{
${ }^{64}$ Véase Corte Suprema, Rol № 65.356-2016, de 19 de diciembre de 2016; y Corte Suprema, Rol № 38.317-2016, de 21 de noviembre de 2018. Un comentario a este fallo en CARMONA (2020), pp. 345-353.

${ }^{65}$ Corte Suprema, Rol № 7.421-2008, de 9 de noviembre de 2009.

${ }^{66}$ Corte Suprema, Rol № 22.393-2019, de 14 de mayo de 2020. En este sentido también: Corte Suprema, Rol № 6.084-2005, de 19 de junio de 2007; y Corte Suprema, Rol № 4396-2018, de 28 de octubre de 2019.

67 Juzgado de Letras y Garantía de Pucón, Rol № V-55-2016, de 25 de junio de 2018.
} 
tipo o forma de propiedad que se conoce como "propiedad indígena"; y un nuevo orden de protección y promoción de esas tierras.

2. La incorporación de este modelo alternativo de propiedad está generando dos grandes polos de tensión al entrar en contacto con la propiedad del derecho común. Así, por un lado, al introducirse una serie de limitaciones a la facultad de disposición se generan problemas de adscripción e ineficacia de los actos y contratos que tengan como objeto esas tierras; y, por otro, al habilitar la entrada de la noción de "territorio indígena", se genera una presión sobre el ejercicio de algunas de las facultades y atributos del dominio de propiedades no indígenas que se ubican dentro este territorio.

3. Respecto de los problemas de adscripción y eficacia referidos, el análisis de la jurisprudencia muestra una tendencia interpretativa orientada a evitar la "desafectación" de la tierra indígena que se fundamentada en la operación de un principio protectorio que ya se encontraba en la LDI y en el Convenio 169, y que ahora parece haber anidado en la mente de los juzgadores.

4. Los principales problemas que hasta la fecha han llegado a los tribunales de justicia dicen relación con el régimen de nulidad vinculado a la transgresión de las reglas protectoras de la tierra indígena que introdujo la LDI; la operación de régimen de regularización de la pequeña propiedad raíz (DL 2.695) en contexto de la Ley Indígena; la aplicación de la LDI a actos y contratos celebrados al amparo de leyes indígenas anteriores; y con las facultades del Conservador respecto de la inscripción de títulos que podrían llevar a la desafectación de tierra indígena.

5. Como se vio, en el diseño legal la protección de la propiedad indígena se articula estableciendo una serie de limitaciones a la facultad de disposición de los propietarios, específicamente, mediante la prohibición de que realicen ciertos tipos de actos y contratos con personas no indígenas. Y por cierto que el análisis jurisprudencial muestra que la transgresión de las normas que introducen prohibiciones traen consigo la ineficacia de los respectivos contratos. Pero, en adición a ello, el análisis jurisprudencial está dando muestras de que la operación del referido orden público de protección, conservación e -incluso-, ampliación de tierras indígenas, está afectando la eficacia de actos y negocios no expresamente regulados en la legislación especial.

\section{BIBLOGRAFÍA CITADA}

ALMONACID, FABIÁN (2009): "El problema de la propiedad de la tierra en el sur de Chile (1850-1930)", en: Historia, Santiago (Vol. 41, № 1), pp. 5-56.

Aguilar, Gonzalo (2005): "El título indígena y su aplicabilidad en el derecho chileno", en: lus et Praxis (Año 11, № 1), pp. 269-295.

AgUILAR, GONZALO (2010): "The constitutional recognition of indigenous people in Latin America", en: Pace International Law Review Online (Año 2, № 2), pp. 44-95.

AldUNATE, CARlos (1997): "Mapuche: gente de la tierra", en: Hidalgo, Jorge (Coord.), Culturas de Chile. Etnografía. Sociedades Indígenas Contemporáneas y su ideología (Santiago, Editorial Andrés Bello), pp. 111-134.

AYLWIN, JOSÉ (2005): "Implementación de Legislación y Jurisprudencia nacional relativa a los derechos de los pueblos indígenas: La experiencia de Chile", en: Seminario de Expertos de la ONU sobre Implementación de Legislación y Jurisprudencia a Nivel Nacional relativa a los Derechos de los Pueblos Indígenas. Tucson, Arizona, Estados Unidos. Disponible en: https://observatorio.cl/wpcontent/uploads/2005/10/doc-trabajo-3-legislacion-y-jurisprudencia-ppii-chile-2005.pdf [visitado el 20 de junio de 2020]. 
BALBontín-Gallo, CRIStóBAL (2019): “Los instrumentos de planificación territorial como mecanismo adecuado para proteger el derecho humano de los indígenas al territorio", en: lus et Praxis (Vol. 25, № 3), pp. 409-424.

BeCA, JUAN PABlo (2020): "La tensión entre el Derecho de Propiedad Individual y la protección de tierras indígenas", en: Fuentes, Rodrigo y Opazo, Valeska (Coords.), El derecho de propiedad: estudios públicos y privados (Santiago, Tirant Lo Blanch), pp. 385-403.

BENGOA, JOSÉ (2000): Historia del Pueblo Mapuche: siglos XIX y XX (Santiago, LOM Ediciones).

BENGOA, JOSÉ (2002): Historia de un conflicto: el estado y los mapuches en el siglo XX (Santiago, Editorial Planeta).

CAlBuCURA, JoRGe (2011): "Consecuencias de la privatización de las reservas indígenas mapuche: Puerto Saavedra, Ruca Traro" en: Nuke Mapuförlaget (Año 2011, № 1). Disponible en: http://www.mapuche.info/wps_pdf/calbucura20110225.pdf [visitado el 20 de junio de 2020].

CANIUqueO, SeRGIO (2006): “Siglo XX en Gulumapu: De la fragmentación del Wallmapu a la unidad nacional mapuche. 1880 a 1978", en: Caniuqueo, Sergio (Coord.), i...Escucha, winka...! Cuatro ensayos de Historia Nacional Mapuche y un epílogo sobre el futuro (Santiago, LOM Ediciones), pp. 129-219.

CARMONA, CRISTÓBAL (2020): “La letra muerta de la Ley Indígena: calificación registral, tierras indígenas e inscripción judicial", en: Revista de Derecho (Valdivia) (Vol. XXXIII, № )1, pp. 345-353.

GONZÁlEZ, HÉCTOR (1986): "Propiedad comunitaria o individual. Las leyes indígenas y el pueblo mapuche", en: Revista Nütram (Año II, № 3), pp. 7-13.

GuZmÁn, Alejandro (1987): "El régimen de la costumbre en las codificaciones civiles de Hispanoamérica y España emprendidas durate el siglo XIX", en: Revista de Estudios HistóricoJurídicos (№ 12), pp. 237-254.

Indígenas, Comisión Verdad Histórica Y Nuevo Trato Con Los Pueblos (2003): Informe de la Comisión Verdad Histórica y Nuevo Trato con los Pueblos Indígenas (Santiago, Coordinación editorial Sergio Molina Monasterios).

LIPSCHUTZ, ALEXANDER (1956): La comunidad indígena en América y en Chile: su pasado histórico y sus perspectivas (Santiago, Editorial Universitaria).

MezA-LopehandíA, Matías (2013a): “El Derecho Internacional de los Derechos Humanos y los pueblos indígenas", en: Aylwin, José (Coord.), Los pueblos indígenas y el derecho (Santiago, LOM Ediciones), pp. 441-521.

MezA-LopehandíA, Matías (2013b): “El Convenio № 169 sobre pueblos indígenas y tribales de la Organización Internacional del Trabajo", en: Aylwin, José (Coord.), Los pueblos indígenas y el derecho (Santiago, LOM Ediciones), pp. 337-439.

MezA-LopehandíA, Matías (2016): "Territorio indígena en el derecho chileno", en: Informe Comisión de Agricultura, en el marco de la discusión del "Proyecto de Ley que Reforma el Código de Aguas" (Boletín $\quad \mathrm{N}^{\circ}$ 7543-12). Disponible en: https://www.bcn.cl/obtienearchivo?id=repositorio/10221/22372/1/FINAL\%20\%20Territorio\%20ind\%C3\%ADgena\%20en\%20el\%20derechos\%20chileno.pdf [visitado el 20 de junio de 2020].

MíGUEZ, RODRIGO (2013): "Estado chileno y tierras mapuche: entre propiedades y territorialidad", en: Olea, Helena (Ed.), Derecho y Pueblo Mapuche (Santiago, Centro de Derechos Humanos UDP), pp. 21-50.

ORMEÑO, HUGO Y OSSES, JORGE (1972): "Nueva legislación sobre tierras indígenas en Chile", en: Cuadernos de la Realidad Nacional (№ 14), pp. 15-45. 
PeÑAILILLO, DANIEL (2019): Los bienes, la propiedad y otros derechos reales, 2a edición (Santiago, Thomson Reuters).

PoBlete, Gustavo (2018): "Los límites de la propiedad indígena y tribal en la jurisprudencia de la Corte Interamericana de Derechos Humanos" en: Henríquez, Miriam y Rajevic, Enrique (Coords.), Derecho de Propiedad. Enfoques de Derecho Público (Santiago, Editorial Der y Universidad Alberto Hurtado), pp. 69-85.

Quezada, CARlos (1995): "Regulación de la Propiedad Indígena y el Principio de Igualdad", en: Revista Academia de Derecho (№ 4), pp. 133-226.

Rodriguez, MARía SARA (2019): “Ley Indígena cestatuto personal o real?”, en: Comisión especial investigadora sobre adquisición de tierras indígenas, lunes 5 de agosto de 2019. Disponible en: https://msararodriguez.wordpress.com/b [visidado el 02 de julio de 2020].

ROJAS, DANIEL (2014): “Análisis conceptual del derecho a la tierra de los pueblos indígenas según el derecho internacional. Tesis para optar al grado de Licenciado en Ciencias Jurídicas Pontificia Universidad Católica de Valparaíso". Disponible en: http://bibliotecadigital.indh.cl/handle/123456789/768 [visitado el 26 de noviembre de 2020].

Ruiz-TAgle, Pablo (2018): "La propiedad en Chile y sus dilemas", en: Revista de Derecho de la Pontificia Universidad Católica de Valparaíso (№ 51), pp. 199-230.

Silva, AlejANDRo (1997): Tratado de Derecho Constitucional, La Constitución de 1980, Bases de la institucionalidad. Nacionalidad y ciudadanía. Justicia Electoral, 2a edición (Santiago, Editorial Jurídica de Chile), tomo IV.

TAPIA, MAURICIO (2005): Código Civil 1855-2005. Evolución y perspectivas (Santiago, Editorial Jurídica de Chile).

TOledo, Víctor (2006): Pueblo mapuche. Derechos colectivos y territorio: Desafíos para la sustentabilidad democrática (Santiago, LOM Ediciones).

VARAS, JUAN (2003): "Limitaciones a la propiedad: Una perspectiva civil", en: Ferrada, Juan (Ed.), La Constitucionalización del Derecho Chileno (Santiago, Editorial Jurídica de Chile), pp. 143-165.

VARAS, JUAN (2007): "Propiedad austral, limitaciones al dominio y valor de los precedentes judiciales", en: Guzmán, Alejandro (Ed.), Estudios de Derecho Civil III (Santiago, Thomson Reuters), pp. 255-271.

\section{JURISPRUDENCIA CITADA}

Corte Interamericana de Derechos humanos: Yake AXa vs. Paraguay (2005), 17 de junio de 2005.

CoRTE Interamericana de DeRechos humanos: Comunidad Indígena SAWhoyamaXa Vs. Paraguay (2006), 29 de marzo de 2006.

VÁsquez y otra Con Conservador de BIEnes Raíces de Temuco (2007): Corte Suprema 19 de junio de 2007 (procedimientoo voluntario), Rol № 6.084-2005, en: www.pjud.cl.

CAÑIUCUL HUICHICOI CON FERnANDEZ BILBAO (2008): Corte Suprema 15 de octubre de 2008 (nulidad absoluta y reivindicación), Rol № 4.897-2007, en: www.pjud.cl.

SAavedra Huentelaf con Forestal AnCHILe LTDA (2008): Corte Suprema 11 de diciembre de 2008 (acción de nulidad absoluta), Rol № 4.384-2007, en: www.pjud.cl.

BRAUN HADIDA Y OTRO (2009): Corte Suprema 9 de noviembre de 2009 (acción voluntaria de requerimiento de inscripción), Rol № 7.421-2008, en: www.pjud.cl.

Venegas Anabalón con CATRilef Antio (2010): Corte Suprema 8 de julio de 2010 (acción de nulidad absoluta), Rol № 5561-2008, en: www.pjud.cl. 
Huenul huenul con Granzotto Brun (2010): Corte Suprema 6 de diciembre de 2010 (acción de nulidad absoluta de contrato), Rol № 6.570-2008, en: www.pjud.cl.

Pineda Rojas con CURINAo ARIAS (2011): Corte Suprema 25 de enero de 2011 (acción de cumplimiento), Rol № 1903-2009, en: www.pjud.cl.

Bravo Cayuñanco con Tiznado (2011): Corte Suprema 17 de junio de 2011 (acción de nulidad absoluta de contrato), Rol № 6.763-2009, en: www.pjud.cl.

GAJARDO CON RIQUelme (2012): Corte de Apelaciones de Temuco 10 de septiembre de 2012 (recurso de protección), Rol № 1.167-2012, en: www.pjud.cl.

Collilef Millar con Peña Sobarzo (2013): Corte Suprema 9 de enero de 2013 (acción de nulidad absoluta), Rol № 8.228-2010, en: www.pjud.cl.

Moreno con Cheuquel (2014): Corte Suprema 5 de mayo de 2014 (oposición a saneamiento), Rol № 9.581-2013, en: www.pjud.cl.

Véjar Reliqueo con BANCo del Estado (2014): Corte Suprema 23 de julio de 2014 (acción de nulidad absoluta), Rol № 5.570-2013, en: www.pjud.cl.

PAILlaLef CON CONADI (2016): Corte Suprema 30 de marzo de 2016 (recurso de protección), Rol № 16.063-2016, en: www.pjud.cl.

Comunidad Indígena Entuco con Municipalidad PAdRe las CASAS (2016): Corte Suprema 4 de abril de 2016 (recurso de protección), Rol № 36.728-2015, en: www.pjud.cl.

Sociedad Agrícola la Cascada con Conservador de Bienes Raíces de Loncoche (2016): Corte Suprema 19 de diciembre de 2016 (recurso de protección), Rol № 65.356-2016, en: www.pjud.cl.

Bravo Cayuñanco con Constructora Morales Hermanos limitada (2017): Corte Suprema 29 de noviembre de 2017 (acción de nulidad absoluta de contrato), Rol № 89.636-2016, en: www.pjud.cl.

CoÑUeCAR CON CABRERA (2018): Corte Suprema 21 de junio de 2018 (acción de nulidad absoluta de contrato), Rol № 7.168-2017, en: www.pjud.cl.

AgUilar CÁRCAMo (2018): Corte Suprema 21 de noviembre de 2018 (recurso de casación), Rol № 38.317-2016, en: www.pjud.cl.

Millaqueo Morel (2019): Corte Suprema 28 de octubre de 2019 (recurso de casación), Rol № 43962018, en: www.pjud.cl.

PAINEQUiR CON Ubilla (2020): Juzgado de Letras y Garantía de Pucón 21 de enero de 2020 (acción de nulidad absoluta), Rol № C-162-2019, en: www.pjud.cl.

Huilipán MARFilio CON TORO VilLAgRán (2020): Corte Suprema 3 de marzo de 2020 (acción de terminación de arrendamiento), Rol № 23194-2018, en: www.pjud.cl.

NAMONCURA CON ARANEDA Y OtROS (2020): Corte Suprema 6 de abril de 2020 (acción de nulidad absoluta), Rol № 19.268-2018, en: www.pjud.cl.

RiverA MuÑoz (2020): Corte Suprema 14 de mayo de 2020 (recurso de casación), Rol № 22.3932019, en: www.pjud.cl.

CAtrilaf con Grez (2020): Corte de Apelaciones de Valdivia 24 de diciembre de 2020 (recurso de apelación), Rol № 393-2020, en: www.pjud.cl.

\section{NORMATIVA CITADA}

LEY № 19.253, Establece normas sobre protección, fomento y desarrollo de los indígenas, y crea la Corporación Nacional de Desarrollo Indígena. Diario Oficial, 5 de octubre de 1993. 
LEY № 17.729, Establece normas sobre indígenas y tierras de indígenas. Transforma la Dirección De Asuntos Indígenas en Instituto de Desarrollo Indígena. Establece disposiciones judiciales, administrativas y de desarrollo educacional en la materia y modifica o deroga los textos legales que señala. Diario Oficial, 13 de abril de 1972.

D.L. № 2.695, Fija normas para regularizar la posesión de la pequeña propiedad raíz y para la constitución del dominio sobre ella. 21 de julio de 1979.

Reglamento S/N, Reglamento del Registro Conservatorio de Bienes Raíces. 24 de junio de 1857. 